\title{
Hoarseness Due to Aortic Arch Aneurysms
}

\author{
Shi-Min Yuan ${ }^{1}, \mathrm{MD}, \mathrm{PhD}$
}

DOI: 10.21470/1678-9741-2019-0352

\begin{abstract}
Objective: To give an overview of the Ortner's syndrome caused by an aortic arch aneurysm.

Methods: By comprehensive retrieval of the pertinent literature published in the past two decades, 75 reports including 86 patients were collected and recruited into this study along with a recent case of our own.

Results: The aortic arch aneurysms causing hoarseness were most commonly mycotic aneurysms. In this patient setting, in addition to the left recurrent laryngeal nerve, trachea was the most commonly affected structure by the aortic arch aneurysm. Surgical/
\end{abstract}

interventional/hybrid treatments led to a hoarseness-relieving rate of $64.3 \%$, much higher than that of patients receiving conservative treatment. However, hoarseness recovery took longer time in the surgically treated patients than in the interventionally treated patients.

Conclusion: The surgical and interventional treatments offered similar hoarseness-relieving effects. Surgical or interventional treatment is warranted in such patients for both treatment of arch aneurysms and relief of hoarseness.

Keywords: Hoarseness. Aneurysm, Infected. Recurrent Laryngeal Nerve. Conservative Treatment. Trachea. Aorta Aneurysm.

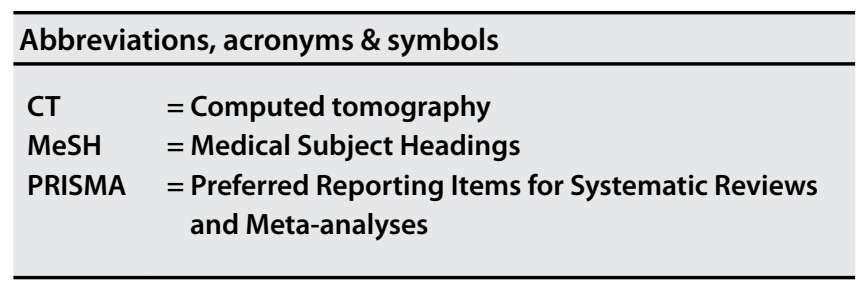

\section{INTRODUCTION}

In 1897, Ortner described a series of three cases of mitral stenosis who were also suffering from hoarseness of voice because of left recurrent laryngeal nerve palsy, and it was then termed as Ortner's syndrome ${ }^{[1]}$. This condition is rare, and its incidence is difficult to ascertain. The cardiovascular etiologies of hoarseness can be congenital, valvular, aortic, or supra-aortic vascular disorders ${ }^{[2]}$. Aortic aneurysm of any etiology can be a risk factor leading to cardiovascular hoarseness, whereas thoracic aortic aneurysms represent only $5 \%$ of the cases $^{[2]}$. Nevertheless,

'The First Hospital of Putian, Teaching Hospital, Fujian Medical University, Putian, People's Republic of China.

This study was carried out at The First Hospital of Putian, Teaching Hospital, Fujian Medical University, Putian, People's Republic of China.
Ortner's syndrome caused by an aortic arch aneurysm is an even rarer entity, and its clinical features, treatments of choice, and patients' outcomes are unknown although sporadic cases are continuously reported. The purpose of this study is to give an overview of the Ortner's syndrome caused by an aortic arch aneurysm.

\section{METHODS}

The Preferred Reporting Items for Systematic Reviews and Meta-analyses (PRISMA) statement guidelines were followed for completing the present meta-analysis. Publications from 2000 to the present time were comprehensively searched in the PubMed database. The Medical Subject Headings (MeSH) terms and keywords that were applied for the literature retrieval included "hoarseness", "dysphonia", "aphonia", "Ortner's syndrome", "cardiovocal syndrome", "left recurrent laryngeal nerve palsy", "left vocal cord palsy", "aneurysm/pseudoaneurysm", and "aortic arch". The screening of the bibliographic references helped to complete the literature retrieval. One hundred and twenty-seven

Correspondence Address:

Shi-Min Yuan

iD https://orcid.org/0000-0002-1773-2959

The First Hospital of Putian, Teaching Hospital, Fujian Medical University

389 Longdejing Street, Putian, People's Republic of China

Zip Code: 351100

E-mail: shiminyuan@126.com 
articles were found related to the topic and keywords in the literature search, and 75 articles, which met the inclusion criteria during preliminary assessment, were included in the review. The exclusion criteria were articles reporting: hoarseness due to (pseudo)aneurysm of other segments of aorta $(n=12)$, aortic arch/ascending aorta dissection $(n=8)$, ductal aneurysm $(n=3)$, aneurysms of the left/right/aberrant right subclavian artery $(n=3)$, cardiomegaly $(n=3)$, right-sided aortic arch without/with Kommerell's diverticulum ( $n=3)$, cervical aortic arch $(n=1)$, and pulmonary hypertension $(n=1)$; hoarseness due to aortic arch aneurysm with no patient information available $(n=8)$; aortic arch aneurysm while patients did not present with hoarseness $(n=5)$; aortic arch repair techniques $(n=3)$; thoracic aorta trauma $(n=1)$; and coarctation of the aorta $(n=1)$.

The data independently extracted from each study were the study population; demographics; clinical symptoms; associated disorders; the size, shape, dimension, extension, location, and nature of the arch aneurysms; treatment of choice; hoarseness recovery; and patients' outcomes.

The IBM SPSS Statistics 22.0 software was used for statistical analysis. The measurement data were expressed in mean \pm standard deviation and were compared by independent sample/paired t-test. The categorical variables were compared by Fisher's exact test. The predictive risk factors for compression of other adjacent organs/tissues were assessed by multinomial logistic regression. $P<0.05$ was considered statistically significant.

\section{RESULTS}

In total, 86 patients were included in the 75 articles ${ }^{[1-75]}$. We recently had a 73-year-old male patient, who presented with two-week hoarseness with laryngoscopic evidence of left vocal cord paralysis. Chest computed tomography showed a giant aortic arch pseudoaneurysm (diameter $6.8 \mathrm{~cm}$ ) with mural thrombosis (Figure 1). Altogether, 87 patients were recruited into this study.
Patients were at the age of $67.1 \pm 13.8$ (range: 28-89; median: 70) years $(n=80)$. There were $69(79.3 \%)$ male and $18(20.7 \%)$ female patients with an absolute male gender predominance $\left(X^{2}=59.8, P<0.001\right)$. There was no age difference between the male and female patients $(67.1 \pm 13.9$ years vs. $70.7 \pm 9.4$ years, $P=0.346)$.

Hoarseness was a sole symptom in 32 (36.8\%) patients ${ }^{[1,9,11,12,18,21,22,31-34,36,41,43,45,47,50,54-56,58,59,62,63,65-68,74,75]}$, a major

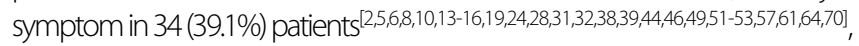
and an accompanying symptom in 21 (24.1\%) patients $^{[3,4,7,17,20,23,25-27,29,30,32,35,37,40,42,48,60,69,72,73]}\left(X^{2}=5.1, P=0.079\right)$.

Except for hoarseness, 45 (51.7\%) patients had 76 other symptoms (Table 1). The duration of hoarseness before current admission was 5.6 \pm 11.7 (range: -0.07-72; median: 2) months ( $n=55)$ (time of hoarseness that occurred after admission was recorded as a minus).

The arch aneurysms were purely arch-affected in 76 (87.4\%) patient $^{[1,2,4,6-18,20-49,52-56,58-61,63-66,68-71,73,74]}$, the aneurysm was extending from the ascending aorta to the aortic arch in four (4.6\%) patients ${ }^{[3,31,57,62]}$, from the aortic arch to the descending aorta in three (3.4\%) patients ${ }^{[51,67,75]}$, and there were archthoracoabdominal aortic aneurysm ${ }^{[19]}$, aneurysm extending from the ascending aorta to the descending aorta ${ }^{[72]}$, arch and left subclavian artery aneurysms ${ }^{[50]}$, and an aortic arch aneurysm with a proximal descending aorta aneurysm ${ }^{[5]}$ in one $(1.1 \%)$ patient, each.

In 27 (31.0\%) patients, the exact locations of the arch aneurysm were described. Most of the aneurysms affect the distal portion of the aortic arch (Table 2).

The etiology of the aneurysmal formation was described in 28 (32.2\%) patients, with mycotic arch aneurysm being a major etiology (Table 3).

The mean maximal diameter of arch aneurysms was $6.8 \pm 2.7$ (range: 3-15; median: 6.4) cm ( $n=55)$. The shapes of arch aneurysms were described for 47 patients: 36 (76.6\%) aneurysms were saccular ${ }^{[1,2,5-7,9,10,13,14,16,18,20,22,25,29,31,35,37,39,45,47,49,50,52,55,56,58,59,63-66,70,71,74,75]}$,
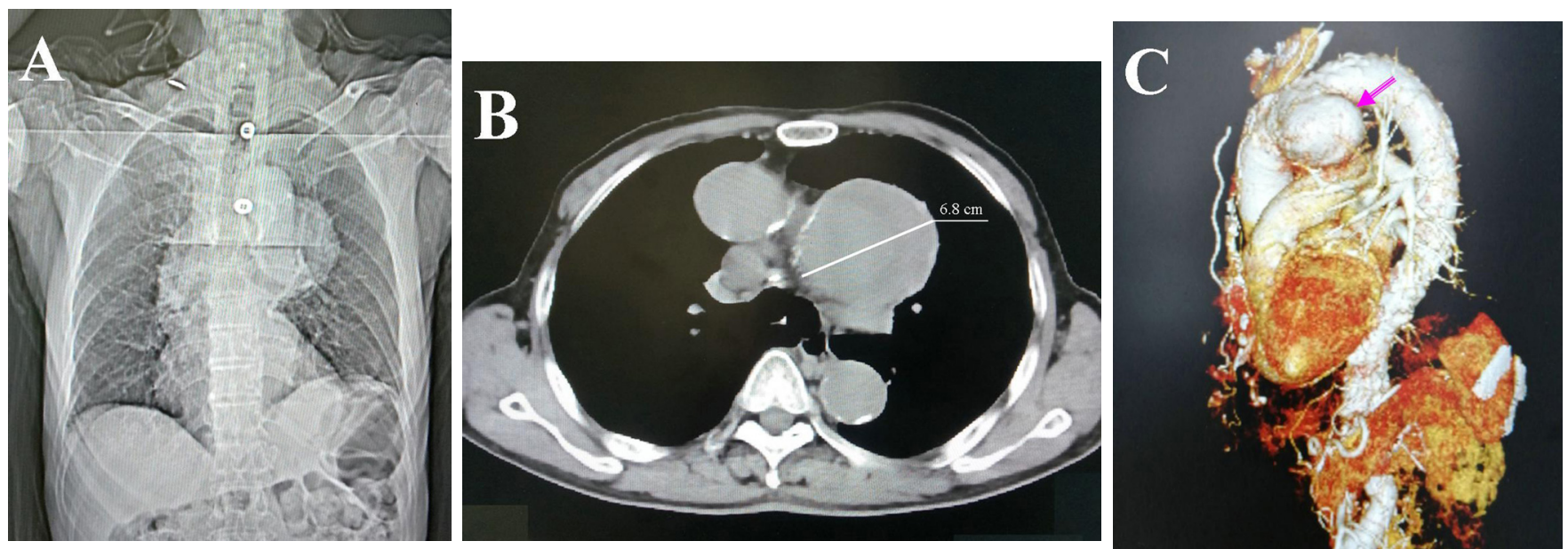

Fig. 1 - Computed tomography (CT) of an aortic arch pseudoaneurysm in a 73-year-old male patient presenting with a two-week hoarseness. (A) The first frame imaging of CT scan showed a protruding aortic arch into the left upper thoracic cavity; (B) an axial view of the aortic arch pseudoaneurysm measuring $6.8 \mathrm{~cm}$ in diameter; and (C) the aortic arch pseudoaneurysm arising from the inferior aspect of the arch on threedimensional CT. 
Table 1. Other symptoms of patients with Ortner's syndrome.

\begin{tabular}{|c|c|}
\hline Symptom & n (\%) \\
\hline $\begin{array}{l}\text { Dyspnea/breathlessness/shortness of } \\
\text { breath }[7,8,13,14,25,26,30,35,49,51,52,60,72,64]\end{array}$ & $14(18.7)$ \\
\hline Cough $[2,16,17,24,27,35,42,46,48,49,51,61,64,73]$ & $14(18.7)$ \\
\hline Chest/back pain $[2-4,10,13,15,19,23,31,32,40,69,70]$ & $13(17.3)$ \\
\hline Dysphagia $^{[3,13,16,19,20,38,42,73]}$ & $8(10.7)$ \\
\hline Fever/fever of unknown origin $[17,29,37,40]$ & $4(5.3)$ \\
\hline Weight loss ${ }^{[7,20,37,49]}$ & $4(5.3)$ \\
\hline Hemosputum/hemoptysis ${ }^{[29,53,48]}$ & $3(4.0)$ \\
\hline Fatigue $\mathrm{e}^{[32,60]}$ & $2(2.7)$ \\
\hline Poor appetite $[2,20]$ & $2(2.7)$ \\
\hline Weakness $^{[2,37]}$ & $2(2.7)$ \\
\hline Choking $^{[39]}$ & $1(1.3)$ \\
\hline Aspiration $^{[32]}$ & $1(1.3)$ \\
\hline Nasal obstruction ${ }^{[5]}$ & $1(1.3)$ \\
\hline Sore throat ${ }^{[5]}$ & $1(1.3)$ \\
\hline Sputum $^{[31]}$ & $1(1.3)$ \\
\hline Dizziness $^{[57]}$ & $1(1.3)$ \\
\hline Headache ${ }^{[57]}$ & $1(1.3)$ \\
\hline Orthopnea ${ }^{[52]}$ & $1(1.3)$ \\
\hline Claudication pain in the $\operatorname{legs}^{[52]}$ & $1(1.3)$ \\
\hline Shock $^{[44]}$ & $1(1.3)$ \\
\hline
\end{tabular}

Table 2. Locations of the arch aneurysms.

\begin{tabular}{l|c}
\multicolumn{1}{c|}{ Location } & $\mathbf{n}(\%)$ \\
\hline Distal $^{[6,17,18,29,31,32,56,75]}$ & $11(40.7)$ \\
\hline Inferior/basal $^{[4,12,13,16,33,35,55,64,71]}$ & $9(33.3)$ \\
\hline Anterior $^{[14,53]}$ & $1(3.7)$ \\
\hline Inferoposterior $^{[11]}$ & $1(3.7)$ \\
\hline Inferolateral $^{[59]}$ & $1(3.7)$ \\
\hline Inferolateral \& anterior $^{[63]}$ & $1(3.7)$ \\
\hline Lateral $^{[7,68]}$ & $1(3.7)$ \\
\hline Posterior & $1(3.7)$ \\
\hline Proximal $^{[5]}$ & $1(3.7)$ \\
\hline
\end{tabular}

nine $(19.1 \%)$ were fusiform ${ }^{[27,42,44,51,54,57,61,62,72]}$, one (2.1\%) was bilobed $^{[73]}$, and one (2.1\%) was irregularly shaped ${ }^{[38]}$. A mural thrombus was present in 34 (20.7\%) patients ${ }^{[1,2,7,8,11-14,18,19,22,29,31,34,38,39,42,45,46,48-52,54-56,60,62,63,68-70]}$. In 12 (13.8\%) patients, the arch aneurysms were pseudoaneurysms ${ }^{[4,17,26,33,36,41,43,46,48,55,73]}$. Left vocal cord paralysis
Table 3. Etiology of aortic arch aneurysms.

\begin{tabular}{l|c}
\hline \multicolumn{1}{c|}{ Etiology } & $\mathbf{n}(\%)$ \\
\hline Mycotic $^{[6,22,28,29,32,37,38,40]}$ & $12(42.9)$ \\
\hline Salmonella $^{[15,29]}$ & $2(16.7)$ \\
\hline Clostridium septicum $^{[38]}$ & $1(8.3)$ \\
\hline Clostridium septicum, Enterobacter, and $^{[40]}$ & $1(8.3)$ \\
\hline Streptococcus $^{[40]}$ & $1(8.3)$ \\
\hline Pseudomonas aeruginosa $^{[32]}$ & $1(8.3)$ \\
\hline Streptococcus dysgalactiae $^{[32]}$ & $1(8.3)$ \\
\hline Candida albicans $^{[32]}$ & $5(41.7)$ \\
\hline Unspecified $^{[6,22,28,32,37]}$ & $11(39.3)$ \\
\hline Atherosclerotic $^{[12,20,28,31]}$ & $3(10.7)$ \\
\hline Penetrating aortic ulceration $^{[4,18,33]}$ & $1(3.6)$ \\
\hline Traumatic $^{[43]}$ & $1(3.6)$ \\
\hline Atherosclerotic/traumatic $^{[34]}$ &
\end{tabular}

Table 4. Other 21 adjacent organs/tissues compressed by aortic arch aneurysms in 13 patients.

\begin{tabular}{|c|c|}
\hline Adjacent organs/tissues & n (\%) \\
\hline Trachea ${ }^{[8,13,20,23,26,72]}$ & $6(30)$ \\
\hline Esophagus $^{[3,13,20]}$ & $3(15)$ \\
\hline Main pulmonary artery ${ }^{[14,23,31]}$ & $3(15)$ \\
\hline Left pulmonary arteries $^{[14,53]}$ & $2(10)$ \\
\hline Right ventricular outflow tract ${ }^{[53]}$ & $1(5)$ \\
\hline $\begin{array}{l}\text { Origin of left carotid \& left subclavian } \\
\text { arteries }^{[20]}\end{array}$ & $1(5)$ \\
\hline Right bronchus ${ }^{[27,67]}$ & $1(5)$ \\
\hline Right hilum $^{[3]}$ & $1(5)$ \\
\hline Right phrenic nerve ${ }^{[3]}$ & $1(5)$ \\
\hline Superior lobe of the left lung ${ }^{[5]}$ & $1(5)$ \\
\hline Superior vena cava ${ }^{[3]}$ & $1(5)$ \\
\hline
\end{tabular}

was evidenced in 39 (44.8\%) patients: by laryngoscopic examination in 34 (87.2\%) patients[2-5,7-9,11,12,14,18,20,21,23-26,33-39,41,42,45-47,52,56-59,62$64,66,68,71,73-75]$, by nasopharyngoscopy in three (7.7\%) patients $[55,69,70]$, and by bronchoscopy in two (5.1\%) patients ${ }^{[48,54]}$. Nevertheless, one patient had right vocal cord paralysis instead ${ }^{[67]}$.

Apart from compression of the left/right recurrent laryngeal nerve by the aortic arch aneurysm, 13 (14.9\%) patients had compressions of other adjacent organs/tissues. The trachea was the most commonly affected organ (Table 4).

In 17 (19.5\%) patients, there was an associated disorder, including arch aneurysm rupture $(n=5)^{[3,30,44,48,69]}$ (one was 
impending rupture $\left.{ }^{[69]}\right)$, aortoesophageal fistula $(n=2)^{[40,48]}$, aortopulmonary fistula $(n=2)^{[17,30]}$, aortic dissection $(n=2)$ [21,75], hemidiaphragmatic paralysis $(n=2)^{[2,52]}$, descending aorta pseudoaneurysm $(n=1)^{[43]}$, iliopsoas muscle abscess with a history of left common iliac artery aneurysm $(n=1)^{[32]}$, left hemothorax $(n=1)^{[72]}$, and pericardial and pleural effusions $(n=1)^{[73]}$.

The predictive risk factors for compressions of other adjacent organs/tissues were assessed by admitting the size $(P=0.059)$, shape $(P=0.712)$, mural thrombus $(P=0.410)$, and false aneurysm $(P=0.999)$ as dependent variables by multinomial logistic regression. Only arch aneurysmal size was a quasi-determinant for the compressions.

The treatment of choice was not described in 18 patients. Thirteen patients refused to receive a surgical/interventional treatment ${ }^{[3,7,14,19,20,22,23,35,39,52,59,60,64]}$. Two patients died suddenly before the treatment started ${ }^{[69,73]}$. One patient was advised to consult the surgeon for possible surgical treatment ${ }^{[49]}$. Two patients were on a follow-up ${ }^{[66,67]}$. Nine patients chose conservative treatment due to their poor conditions that could not support a surgical treatment ${ }^{[2,11,44,47,54,61,71,72,74]}$. Of the remaining 42 patients, 19 (19/42, 45.2\%) patients underwent a surgical treatment (an arch replacement in 16 [16/19, 84.2\%] patients ${ }^{[5,10,12,15,21,27,29-32,38,48,65]}$, patch reconstruction of the aorta in two $[2 / 19,10.5 \%]$ patients $^{[13,17]}$, and the operation method was not indicated in one $[1 / 19,5.3 \%]$ patient $\left.{ }^{[57]}\right), 18$ patients $(18 / 42$, 42.9\%) received an endovascular aortic repair by a stent graft insertion ${ }^{[6,26,28,33,34,40-42,56,58,75]}$, and five $(5 / 42,11.9 \%)$ patients were treated with hybrid procedures, including stent graft plus woven Dacron vascular graft in two patients ${ }^{[50,53]}$, and endovascular frozen elephant trunk replacement of the ascending aorta and aortic arch ${ }^{[70]}$, left carotid-subclavian bypass plus stent graft ${ }^{[4]}$, and open-arch repair and descending aorta stent grafting ${ }^{[43]}$ in one patient, each.

The surgical approach for open arch replacement was described for eight patients: via a median sternotomy in six (6/8, $75 \%)$ patients ${ }^{[25,29,30,38,53,70]}$ and via a left lateral thoracotomy in two $(2 / 8,25 \%)$ patients $^{[5,12]}$.

Cardiopulmonary bypass technique was described for 10 patients: partial cardiopulmonary bypass with no heart arrest in one (10\%) patient ${ }^{[13]}$, full cardiopulmonary bypass in four (40\%) patients ${ }^{[5,12,50,70]}$, and deep hypothermic circulatory arrest with cerebral perfusion in five (50\%) patients ${ }^{[15,25,29,30,38]}$.

In 32 patients, the hoarseness-relieving effect was reported: the hoarseness was relieved in 12 (37.5\%) patients, improved in seven (21.9\%) patients (improved by injection of hyaluronic acid for voice in one patient $\left.{ }^{[74]}\right)$, and persisted in 13 (40.6\%) patients $\left(X^{2}=2.9, P=0.234\right)$. The total effective rate was $59.4 \%$ (19/32). The hoarseness recovery, improvement, and persistent rates did not differ between the surgical and interventional treatment groups (Table 5). However, the total effective rate of the patients receiving surgical/interventional/hybrid treatments was much higher than that of patients with conservative treatment $(64.3 \%$ [18/28] vs. $\left.0 \%[0 / 4], X^{2}=5.9, P=0.028\right)$. Time for hoarseness relief was much shorter in the interventionally treated patients than in the open surgically treated patients (Table 6).

Patients were on a follow-up of $8.3 \pm 7.2$ months $(n=25)$. Patients' outcomes were known for 59 patients: 36 (61.0\%) patients recovered, one (1.7\%) patient improved, four (6.8\%)

Table 5. Hoarseness-relieving effects with different treatments of aortic arch aneurysm.

\begin{tabular}{l|c|c|c}
\multicolumn{1}{c|}{ Treatment } & Recovered & Improved & Persisted \\
\hline Surgical $(\mathrm{n}=10)$ & $4(37.5)$ & $3(37.5)$ & $3(25)$ \\
\hline Interventional $(\mathrm{n}=16)$ & $7(38.5)$ & $3(15.4)$ & $6(46.2)$ \\
\hline Hybrid $(\mathrm{n}=2)$ & $1(50)$ & & $1(50)$ \\
\hline Conservative $(\mathrm{n}=4)$ & & & $4(100)$ \\
\hline$X^{2}$ (surgical vs. interventional) & 0.0 & 0.4 & 0.2 \\
\hline$P$-value (surgical vs. interventional) & 1.000 & 0.644 & 1.000 \\
\hline
\end{tabular}

Table 6. Hoarseness-relieving time after surgical/interventional/hybrid treatment (months).

\begin{tabular}{l|c|c|c}
\multicolumn{1}{c|}{ Treatment } & Recovered & Improved & Persisted \\
\hline Surgical $(\mathrm{n}=8)$ & $18.0 \pm 8.5$ & 1 & $20.3 \pm 9.0$ \\
\hline Interventional $(\mathrm{n}=13)$ & $3.6 \pm 2.8$ & $0.3,3$ & 1 \\
\hline Hybrid $(\mathrm{n}=1)$ & 3 & -- & -- \\
\hline$t$-value (surgical vs. interventional) & 3.217 & -- & -- \\
\hline -value (surgical vs. interventional) & 0.015 & -- & -- \\
\hline
\end{tabular}


Table 7. Patients' outcomes subjected to different treatments.

\begin{tabular}{l|c|c|c|c|c}
\multicolumn{1}{c|}{ Treatment } & Recovered & Improved & Complicated & Unchanged & Died \\
\hline Surgical $(n=23)$ & $21(91.3)$ & & $1(4.3)$ & & $1(4.3)$ \\
\hline Interventional $(n=16)$ & $12(75)$ & & $3(18.8)$ & & $1(6.3)$ \\
\hline Hybrid $(n=3)$ & $3(100)$ & & & & \\
\hline Conservative $(n=14)$ & & $1(7.1)$ & & $9(64.3)$ & $4(28.6)$ \\
\hline Total $(n=56)$ & $36(64.3)$ & $1(1.8)$ & $4(7.1)$ & $9(16.1)$ & $6(10.7)$ \\
\hline
\end{tabular}

patients were complicated and eventually recovered after treatment, nine (15.3\%) patients' conditions did not change, and nine (15.3\%) patients died. The total effective rates showed a significant difference between the four treatment groups (91.3\% vs. $75 \%$ vs. $100 \%$ vs. $\left.7.7 \%, X^{2}=30.3, P<0.001\right)$, whereas the mortality rates did not differ ( $4.3 \%$ vs. $6.3 \%$ vs. $0 \%$ vs. $28.6 \%$, $x^{2}=6.3, P=0.096$ ) (Table 7).

\section{DISCUSSION}

The left recurrent laryngeal nerve arises from the left vagus nerve at the level of the aortic arch curve, and then it curves around the aorta on the outer side of the ligamentum arteriosum ascending along the tracheoesophageal groove. This prolonged course makes it vulnerable to injury by the lesions of the surrounding structures ${ }^{[54]}$.

Hoarseness of voice is a frequent presentation of otolaryngology diseases due to a neoplastic, surgical, idiopathic, traumatic, central, or infectious etiology. Nevertheless, cardiovascular hoarseness, especially hoarseness due to an aortic arch aneurysm, is very rare. The bulging cardiovascular structures can frequently compress the left recurrent laryngeal nerve leading to left vocal cord paralysis, rendering patients presenting with hoarseness ${ }^{[2]}$.

In addition to hoarseness, the common symptoms of patients with Ortner's syndrome were dyspnea and dysphagia[ ${ }^{[2,73]}$. However, in this patient setting with an arch aneurysm as an etiology, the common symptoms were dyspnea, cough, and chest pain.

The etiology of thoracic aortic aneurysm can be typically categorized as heritable or degenerative. In the cohort of patients with Ortner's syndrome due to an aortic aneurysm, the underlying etiologies can be degenerative, traumatic, dissecting, and atherosclerotic, all pathological changes of the aorta that create compression on the left recurrent laryngeal nerve. In this report, mycotic infection prevailed the underlying causes of the aortic arch aneurysms, followed by an atherosclerotic etiology.

The aortic arch aneurysms lead not only to compression of the left recurrent laryngeal nerve, but also compression of other adjacent organs/tissues in one-fifth of the Ortner's syndrome patients, with the trachea being the most affected organ. Moreover, the arch aneurysmal size was found to be a quasideterminant leading to the adjacent organ compression as disclosed by the present study.
Indirect laryngoscopy becomes a more common technique for the diagnosis of vocal cord palsy. Further investigations include echocardiography, computed tomography, and magnetic resonance imaging. Early diagnosis of Ortner's syndrome is essential for starting timely treatment, restoring vocal cord function, and avoiding permanent damage of the patients.

The treatment of choice of aortic arch aneurysms can be an open surgery or an interventional procedure. Usually, the conventional treatment of mycotic aneurysms is open aneurysmectomy, along with the debridement of the adjacent infectious tissues. In situ tube graft insertion or extra-anatomic bypass grafting may be at risk of infection, and thus with less promising long-term outcomes ${ }^{[6]}$. In spite of advanced diagnostic modalities and refined interventional therapies of today, the mortality rate of surgical treatment of mycotic aneurysm remains high. Endovascular grafts have been widely used for the treatment of aortic aneurysms as a very appealing alternative to open aortic surgery, in particular for the patients in whom surgical procedures carry high risks ${ }^{[6]}$. The increasingly sophisticated interventional technology has enabled the treatment of lesions of the critical segments of the aorta, such as the thoracic and arch levels ${ }^{[6]}$.

The recovery in hoarseness is highly variable. In a comprehensive review including 58 patients with Ortner's syndrome, the hoarseness resolved in $44.8 \%$, improved in $29.3 \%$, persisted in 22.4\%, and exacerbated in 3.5\% of patients. The present study based on a cohort of patients with aortic arch aneurysm revealed a bit lower recovery and improving rates, but higher persisted rate of hoarseness. This might be explained by the fact that long-term compression of the left recurrent laryngeal nerve by an aortic aneurysm may take longer time to recover.

Morales et al. ${ }^{[28]}$ described that aneurysm size increase but no endoleak was responsible for the persistent hoarseness after endovascular therapy of the aortic aneurysms, whereas aortic aneurysm size decrease was not necessarily associated with hoarseness relief after the procedure ${ }^{[28]}$. The present study illustrated that the surgical and interventional therapies offered similar hoarseness-relieving effects; and time for hoarseness relief was much shorter in the interventionally treated patients than in the surgically treated patients. It hinted that interventional therapy might be a treatment of choice that could lead to a higher hoarseness-relieving rate. 


\section{CONCLUSION}

Aortic arch aneurysms may cause compression of the left recurrent laryngeal nerve and other adjacent organs/tissues as well. The overall hoarseness-relieving (including recovery and improvement) rate of patients receiving non-conservative treatments was $64.3 \%$, much higher than those with conservative treatment. However, hoarseness recovery took longer time in the surgically treated patients than in the interventionally treated patients. Surgical or interventional treatment is warranted in such patients for the treatment of arch aneurysms and for hoarseness recovery as well.

\section{No financial support. \\ No conflict of interest.}

\section{Author's roles \& responsibilities}

SMY Substantial contributions to the conception or design of the work; acquisition, analysis, and interpretation of data for the work; drafting the work and revising it critically for important intellectual content; agreement to be accountable for all aspects of the work in ensuring that questions related to the accuracy or integrity of any part of the work are appropriately investigated and resolved; final approval of the version to be published

\section{REFERENCES}

1. Subramaniam V, Herle A, Mohammed N, Thahir M. Ortner's syndrome: case series and literature review. Braz J Otorhinolaryngol. 2011;77(5):559-62. doi:10.1590/s1808-86942011000500004.

2. Sarangi PK, Hui P, Sagar HS, Kisku DK, Mohanty J. Combined left recurrent laryngeal nerve and phrenic nerve palsy: a rare presentation of thoracic aortic aneurysm. J Clin Diagn Res. 2017;11(5):TD01-2. doi:10.7860/ JCDR/2017/25035.9765.

3. Akhtar J, Siddiqui MA, Khan NA, Alam MA. Right phrenic nerve palsy: a rare presentation of thoracic aortic aneurysm. Malays J Med Sci. 2013;20(4):98101.

4. Al Kindi AH, Al Kindi FA, Al Abri QS, Al Kemyani NA. Ortner's syndrome: cardiovocal syndrome caused by aortic arch pseudoaneurysm. J Saudi Heart Assoc. 2016;28(4):266-9. doi:10.1016/j.jsha.2016.02.006.

5. Ali Shah MU, Siddiqi R, Chaudhri MS, Khan AA, Chaudhry I. Aortic aneurysm: a rare cause of Ortner's syndrome. J Coll Physicians Surg Pak. 2014;24(4):282-4.

6. Alpagut U, Ugurlucan M, Kafali E, Surmen B, Sayin OA, Guven K, et al. Endoluminal stenting of mycotic saccular aneurysm at the aortic arch. Tex Heart Inst J. 2006;33(3):371-5.

7. Bozbaş SS, Akçay S, Ulu EK, Büyüklü F, Bozbaş H. Cardiovocal (ortner's) syndrome: an unusual vascular complication. Türkiye Klinikleri Arch Lung. 2010;11(1):39-41.

8. Brunhuber $C$, Le Borgne P. Hoarseness as the initial symptom of aortic arch aneurysm. Ann Thorac Surg. 2016;102(4):e365. doi:10.1016/j. athoracsur.2016.04.065.

9. Duda R, Neagu A. Left vocal cord paralysis - as the presenting sign of an aortic arch aneurysm (cardiovocal syndrome). A case report. Roman J Rhinol. 2014;4(15):171-4.

10. Ejazi MA, Alam MM, Shameem M, Bhargava R, Adil Wafi CG, Salauddin.
Thoracic aortic aneurysm: a rare cause of elevated hemidiaphragm. Lung India. 2016;33(4):430-3. doi:10.4103/0970-2113.184917.

11. Fennessy BG, Sheahan P, McShane D. Cardiovascular hoarseness: an unusual presentation to otolaryngologists. J Laryngol Otol. 2008;122(3):327-8. doi:10.1017/S0022215107008110.

12. Fujimura T, Yagi K, Ikeya E, Yamaguchi M, Orii M, Inamura S. A patient who underwent surgical treatment of an adult-type aneurysm in the nonpatent arterial duct. Tokai J Exp Clin Med. 2005;30(4):227-31.

13. Garrido JM, Esteban M, Lara J, Rodriguez-Vazquez JF, Verdugo-Lopez S, Lopez-Checa S. Giant aortic arch aneurysm and cardio-vocal syndrome: still an open-surgery indication. Cardiol Res. 2011;2(6):304-6. doi:10.4021/cr101w.

14. Gulel O, Elmali M, Demir S, Tascanov B. Ortner's syndrome associated with aortic arch aneurysm. Clin Res Cardiol. 2007;96(1):49-50. doi:10.1007/ s00392-006-0454-z.

15. Hamamoto H, Miyamoto S, Anai H, Sako H, Iwata E, Hadama T. Successful treatment of a salmonella aortic arch aneurysm. Jpn J Thorac Cardiovasc Surg. 2003;51(2):59-61. doi:10.1007/BF02719168.

16. Dutra BL, Campos Lda C, Marques Hde C, Vilela VM, Carvalho RE, Duque AG. Ortner's syndrome: a case report and literature review. Radiol Bras. 2015;48(4):260-2. doi:10.1590/0100-3984.2013.1836.

17. Kalra DK, Zoghbi WA. Hoarseness, hemoptysis and a hole in the aorta: a case review. Echocardiography. 2003;20(3):293-4. doi:10.1046/j.15408175.2003.03030.x.

18. Klee K, Eick C, Witlandt R, Gawaz M, Didczuneit-Sandhop B. Unilateral recurrent nerve palsy and cardiovascular disease - Ortner's syndrome. J Cardiol Cases. 2016;15(3):88-90.

19. Kuan WS, Lee SK, Suat Ooi SB. Chronic voice hoarseness: when is it an emergency? Eur J Emerg Med. 2007;14(6):360-2. doi:10.1097/ MEJ.0b013e3280bef945.

20. Kyaw WA, Lim CY, Khali MAM, Lim KC, Chong VH, Tan J. A fatal case of Ortner's syndrome and dysphagia aortica secondary to rapidly expanding mycotic thoracic aortic aneurysm in a chronic kidney disease patient. SAGE Open Med Case Rep. 2018;6:2050313X18799247. doi:10.1177/2050313X18799247.

21. Latus J, Franke U, Alscher MD, Braun N. A 56-year-old woman with stressinduced hoarseness. BMJ Case Rep. 2012;2012:bcr0120125688. doi:10.1136/ bcr.01.2012.5688.

22. Liao YY, Lin HJ, Chen KT. Cardiovocal syndrome arising from gas-forming mycotic aneurysm of the thoracic aorta. J Emerg Med. 2013;45(5):e167-8. doi:10.1016/j.jemermed.2013.04.038.

23. Llerena L, Marcos-Gutiérrez Y, Mendoza-Rodríguez V, Olivares-Aquiles E. A patient complaining of hoarseness with an aneurysm of the aortic arch (Ortner's syndrome) and a left intrathoracic goiter. Internet J Radiol. 2008:9(2):1-4.

24. Mathai J, Swapna UP. Hoarseness as a presenting feature of aortic arch aneurysm. Indian J Otolaryngol Head Neck Surg. 2006;58(3):309-10. doi:10.1007/BF03050855.

25. Matteucci ML, Rescigno G, Capestro F, Torracca L. Aortic arch patch aortoplasty for Ortner's syndrome in the age of endovascular stented grafts. Tex Heart Inst J. 2012;39(3):401-4.

26. Menon MC, Benjam in S, Paul M, Knohl SJ. Ortner syndrome in an elderly vasculopath. South Med J. 2008;101(12):1279. doi:10.1097/ SMJ.0b013e318185732d.

27. Miller CP, Firoozan S, Woo EK, Apps A. Chronic cough: a herald symptom of thoracic aortic aneurysm in a patient with a bicuspid aortic valve. BMJ Case Rep. 2014;2014:bcr2014205005. doi:10.1136/bcr-2014-205005.

28. Morales JP, Chan YC, Bell RE, Reidy JF, Taylor PR. Endoluminal repair of distal aortic arch aneurysms causing aorto-vocal syndrome. Int J Clin Pract. 2008;62(10):1511-4. doi:10.1111/j.1742-1241.2006.01282.x.

29. Nakamura Y, Kawachi K, Imagawa H, Watanabe Y, Hamada Y, Tsunooka N. Mycotic aneurysm of the aortic arch due to salmonella. Jpn J Thorac Cardiovasc Surg. 2003;51(6):253-5. doi:10.1007/s11748-003-0024-5.

30. Nishimura Y, Okamura Y, Uchita S, Honda K. Abrupt rupture of an aortic arch aneurysm into the pulmonary artery. Eur J Cardiothorac Surg. 2009;36(1):2123. doi:10.1016/j.ejcts.2009.03.007

31. Ohki M. Thoracic saccular aortic aneurysm presenting with recurrent laryngeal nerve palsy prior to aneurysm rupture: a prodrome of thoracic aneurysm rupture? Case Rep Otolaryngol. 2012;2012:367873. doi:10.1155/2012/367873.

32. Okada K, Yamanaka K, Sakamoto T, Inoue T, Matsumori M, Kawakami F, 
et al. In situ total aortic arch replacement for infected distal aortic arch aneurysms with penetrating atherosclerotic ulcer. J Thorac Cardiovasc Surg. 2014;148(5):2096-100. doi:10.1016/j.jtcvs.2014.02.015.

33. Sadat U, Titchner A, Noor N, Naik J, Boyle JR. Endovascular repair of a penetrating thoracic aortic ulcer presenting with left recurrent laryngeal nerve palsy. Vasc Endovascular Surg. 2007;41 (6):556-8. doi:10.1177/1538574407305460

34. Semionov A, Kosiuk J. Ortner syndrome secondary to aortic aneurysm. Radiol Case Rep. 2016;12(1):29-30. doi:10.1016/j.radcr.2016.11.024.

35. Shahul HA, Manu MK, Mohapatra AK, Magazine R. Ortner's syndrome. BMJ Case Rep. 2014;2014:bcr2013200950. doi:10.1136/bcr-2013-200950.

36. Srinivasan A, Agarwal R. Cardiovocal syndrome. Monaldi Arch Chest Dis. 2011;75(4):241-2. doi:10.4081/monaldi.2011.212.

37. Tanyaowalak W, Sunthornyothin S, Luengtaviboon K, Suankratay C, Kulwichit W. Mycotic aneurysm caused by burkholderia pseudomallei with negative blood cultures. Scand J Infect Dis. 2004;36(1):68-70. doi:10.1080/00365540310017465.

38. Tokmaji G, Gosev I, Kumamaru KK, Bolman RM 3rd. Mycotic aneurysm of the aortic arch presenting with left vocal cord palsy. Ann Thorac Surg. 2013;96(1):302-5. doi:10.1016/j.athoracsur.2012.11.033.

39. Tsai WC, Wang $\mathrm{CH}$, Chen HC. Cardiovocal syndrome secondary to a giant aortic arch aneurysm. Eur Geriatr Med. 2015;6(1):63-4. doi:10.1155/2016/9867942.

40. Van Doorn RC, Reekers J, de Mol BA, Obertop H, Balm R. Aortoesophageal fistula secondary to mycotic thoracic aortic aneurysm: endovascular repair and transhiatal esophagectomy. J Endovasc Ther. 2002;9(2):212-7. doi:10.1 $177 / 152660280200900213$.

41. Wunderlich C, Wunderlich O, Tausche AK, Fuhrmann J, Boscheri A, Strasser RH. Ortner's syndrome or cardiovocal hoarseness. Intern Med J. 2007;37(6):418-9. doi:10.1111/j.1445-5994.2007.01341.x.

42. Zangirolami AC, Oliveira FV, Tepedino MS. Ortner's syndrome: secondary laryngeal paralysis caused by a great thoracic aorta aneurysm. Int Arch Otorhinolaryngol. 2015:19(2):180-2. doi:10.1055/s-0034-1397331.

43. Zhu P, Yang Q, Qiu F, Liao C. Post traumatic large pseudoaneurysms of the aortic arch and descending aorta. Eur J Cardiothorac Surg. 2009;35(3):535. doi:10.1016/j.ejcts.2008.11.031.

44. Abd Samat AH, Embong H. Ortner's syndrome: focused cardiac ultrasound and rapid ultrasound in shock examination at emergency department unfold the life-threatening cause for a cardiovocal condition. Hong Kong J Emerg Med. 2018;25(5):293-7. doi:10.1177/1024907918755163.

45. Annema JT, Brahim JJ, Rabe KF. A rare cause of Ortner's syndrome (cardiovocal hoarseness). Thorax. 2004;59(7):636. doi:10.1136/thx.2003.020503.

46. Bagul M, Mehra R, Agrawal P. Cardiovocal or Ortner's syndrome due to aortic arch pseudoaneurysm. J Case Rep. 2016;6(3):420-3. doi:10.17659/01.2016.0102.

47. Bajpai J, Kant S, Kar A, Pradhan A. An unusual case of cardiovocal syndrome. Chrismed J Health Res. 2019;6(2):114-6. doi:10.4103/cjhr.cjhr_115_18.

48. Che GW, Chen J, Liu LX, Zhou QH. Aortic arch aneurysm rupture into the lung misdiagnosed as lung carcinoma. Can J Surg. 2008;51(4):E91-2.

49. Elzamzamy UA, Joharjy IA. Thoracic aortic aneurysm presenting only as vocal cord paralysis. Neurosciences (Riyadh). 2007;12(3):245-8.

50. Iguro Y, Arata K, Yamamoto H, Masuda H, Sakata R. A new concept in distal arch aneurysm repair with a stent graft. J Thorac Cardiovasc Surg. 2002;123(2):378-80. doi:10.1067/mtc.2002.119330.

51. Jaafar R, Mohamad I. Hoarseness as the sole symptom of an impending thoracic aneurysm rupture? Malays Fam Physician. 2014;9(1):25-7.

52. Joseph TK, Nair R. Combined recurrent laryngeal and phrenic nerve paralysis due to aortic arch aneurysm. Int J Phonosurg Laryngol. 2013;3(2):58-60. doi:10.5005/jp-journals-10023-1064.

53. Kochi K, Okada K, Watari M, Orihashi K, Sueda T. Hybrid endovascular stent grafting for aortic arch aneurysm with aortopulmonary fistula. J Thorac Cardiovasc Surg. 2002;123(2):363-4. doi:10.1067/mtc.2002.119061.
54. Kodali S, Trilochan BP, Pradhan S, Patnaik J, Dash M. Aortic aneurysm: a rare cause of Ortner's syndrome. J Evol Med Dent Sci. 2014;58(3):13199-202. doi:10.14260/jemds/2014/3756.

55. Kumar A, Dubey KP, Gupta A, Baruah B, Rai A. Ortner's syndrome: a rare cause of hoarseness. Online J Health Allied Scs. 2014;13(3):6.

56. Lew WK, Patel K, Haqqani OP, Weaver FA. Endovascular management of hoarseness due to a thoracic aneurysm: case report and review of the literature. Vasc Endovascular Surg. 2009;43(2):195-8. doi:10.1177/1538574408324616.

57. Lin WS, Cheng CA. Ortner's syndrome. Acta Neurol Taiwan. 2011;20(4):281-2.

58. Manunga J. Endovascular repair of aortic arch aneurysm with surgeonmodified fenestrated stent graft. Aorta (Stamford). 2018;6(2):70-4. doi:10.1055/s-0039-1677810. doi: 10.1055/s-0039-1677810.

59. Norly S, Noorizan Y, Ros'aini P. Thoracic aortic aneurysm presenting as vocal cord paralysis. Int Med J Malaysia. 2013;12(1):67-8.

60. Özyurtlu F, Acet H, Bilik MZ, Tasal A. [Ortner's syndrome caused by dissecting aortic aneurysm]. Türk Kardiyol Dern Arş. 2013;41 (3):225-7. doi:10.5543/ tkda.2013.47935. Turkish.

61. Palanisamy V, Doshi KS, Tengku Nun Ahmad TE, Abu Bakar MZ, Rajagopalan R. Ortner's syndrome: a rare cause of unilateral vocal cord paralysis. Glob J Medical Clin Case Rep. 2017;4(3):69-71. doi:10.17352/2455-5282.000051.

62. Passi P, Singh S, Passi B. Large fusiform aortic aneurysm with mural thrombus - a rare cause of hoarseness of voice: a case report. Indian J Med Spec. 2017;8:206-8. doi:10.1016/j.injms.2017.07.004.

63. Praveen S, Baiju R, Vijayalakshmic, Radhakrishnand W. Cardio vocal syndrome - revisited. Kerala Heart J. 2016; 6(2):xx-xx.

64. Rai SP, Acharya V. An unusual case of recurrent laryngeal nerve palsy presenting as hoarseness due to an aortic arch saccular aneurysm causing neurovascular conflict! Ann Indian Acad Otorhinolaryngol Head Neck Surg. 2017;1(1):32-3. doi:10.4103/aiao.aiao_3_18.

65. Rao A, Mathur M, Veivers D. Ortner's: a cardiovocal syndrome. Heart Lung Circ. 2019;28(Suppl 3):S101. doi:10.1016/j.hlc.2019.02.105.

66. Righini CA, Nadour K, Reyt E. Hoarseness revealing a rare pathology. Eur Ann Otorhinolaryngol Head Neck Dis. 2013;130(2):103-6. doi:10.1016/j. anorl.2012.09.006.

67. Rizvi MM, Singh RB, Jain A, Sarkar A. Asymptomatic aortic aneurysm causing right vocal cord palsy and hoarseness: a rare presentation. Anesth Essays Res. 2014;8(3):397-400. doi:10.4103/0259-1162.143157.

68. Sarin V, Bhardwaj B. Ortner's syndrome-A rare cause of hoarseness: its importance to an otorhinolaryngologist. Iran J Otorhinolaryngol. 2016;28(85):163-7.

69. Sim MY, Lim YC, So SC, Zhang J, Teo DB. A hoarse warning: Ortner's syndrome. Am J Med. 2018;131(12):1460-2. doi:10.1016/j.amjmed.2018.07.036.

70. Tan TXZ, Balakrishnan T, Lam MHH, Chui YY, Cheng LT. A case of hoarseness with acute back pain - cardiovocal syndrome revisited. J Radiol Case Rep. 2019;13(7):21-8.

71. Vlachou PA, Karkos CD, Vaidhyanath R, Entwisle J. Ortner's syndrome: an unusual cause of hoarse voice. Respiration. 2008;75(4):459-60. doi:10.1159/000091041.

72. Wijesinghe SNR, Yasaratne BMGD, Madegedara RMD. Silent rupture of aortic aneurysm mimicking lung malignancy. Indian J Chest Dis Allied Sci. 2013;55(2):113-5.

73. Wu JT, Lai YF. Hoarseness as a first manifestation of aortotracheal fistula. Am J Emerg Med. 2009;27(8):1019.e1-3. doi:10.1016/j.ajem.2008.12.022.

74. Yoon MH, Kim EH, Ryu IS. A case of left vocal cord paralysis caused by aortic arch aneurysm: a variant of Ortner's syndrome. J Korean Soc Laryngol Phoniatr Logop. 2015;26(2):141-3. doi:10.22469/jks/p.2015.26.2.141.

75. Zheng XZ, Chu YH, Tsai CS, Lin CY. Successful thoracic endovascular aortic repair in Ortner's syndrome. Ann Vasc Surg. 2019;57:275.e9-275.e12. doi:10.1016/j.avsg.2018.10.033 